\title{
Dependência da trajetória e mudança institucional nos processos de desenvolvimento
}

Path Dependence and Institutional Change in Development Processes

O debate sobre determinantes estruturais dos processos de desenvolvimento das sociedades contemporâneas é amplo e multifacetado. Duas vertentes especialmente profícuas dessa literatura enfatizam os legados institucionais e os elementos de dependência da trajetória, de um lado, e as teorias que se apoiam na dinâmica política e social dessas sociedades para tentar explicar aqueles fatores estruturais.

Duas recentes obras representativas dessas vertentes são Kurtz (2013) e sua abordagem sociocêntrica ou sociofundacional de construção estatal, e Huber e Stephens (2012), com sua teoria das constelações de poder. Defende-se aqui que elas são ferramentas promissoras para contribuir com o avanço da agenda de pesquisa sobre desenvolvimento no Brasil.

A análise dessas contribuições recentes à literatura sobre dependência da trajetória e mudança institucional busca apontar pontos de convergência entre elas e também as possibilidades de seu uso para interpretar a experiência brasileira de desenvolvimento, por meio da identificação de elementos analíticos úteis à compreensão da trajetória política e institucional do país.

O artigo está organizado em três partes além desta introdução. Nas próximas duas seções são sintetizadas e discutidas as contribuições teóricas de Kurtz (2013) e de Huber e Stephens (2012), respectivamente, aplicadas à interpretação de aspectos cruciais do percurso político e institucional

É doutor em ciência política pela Universidade de Brasília (UnB). E-mail: kleberch@unb.br. 
brasileiro; na seção final, conclui-se com uma tentativa de combinar esses dois quadros teóricos para gerar hipóteses explicativas do desenvolvimento brasileiro recente.

\section{Dependência da trajetória e fundamentos sociais da ordem institucional}

Ao investigar a construção do Estado na América Latina em perspectiva comparada, Kurtz (2013) parte da comparação de três tragédias latino-americanas - os terremotos ocorridos no Chile e no Haiti, em 2010, e a epidemia de cólera no Peru, no início dos anos 1990 - para realçar a enorme diferença entre esses países ao enfrentarem aquelas catástrofes.

Considerando melhor o modo como o Chile enfrentou os problemas decorrentes de um terremoto de magnitude muito superior ao que acometeu o país caribenho, assim como as dificuldades do Peru contra o cólera, o autor formula o conjunto de questões que motiva o livro: por que alguns Estados são tão mais capazes de alcançar uma governança efetiva do que outros? O que explica a enorme variação observada na capacidade dos diferentes Estados em impor a obediência às leis e em implementar políticas públicas básicas? E, por fim, o que torna os Estados fortes ou fracos em termos de sua capacidade para gerenciar suas funções básicas, impor o núcleo de suas políticas públicas e regular o comportamento privado?

Uma vez que a eficácia institucional não se relaciona apenas com riqueza ou capacidade fiscal, Kurtz procura suas fontes no que denomina poder institucional ou poder de governança, definido como a capacidade do Estado para induzir cidadãos, empresas e organizações a agirem de modos que não agiriam na ausência de seu poder administrativo e regulatório.

$\mathrm{O}$ autor sustenta que o fato de cidadãos de países institucionalmente fortes terem maior propensão a agir em conformidade com as normas é uma manifestação, no nível micro, desse poder de governança, cujas características centrais, no nível macro, são a imposição uniforme e geral da obediência às leis (Estado de direito), a provisão de bens públicos, a eficácia militar e a capacidade de gerar recursos fiscais para tornar tudo isso possível.

Para os processos de construção do Estado e de desenvolvimento, a robustez das instituições estatais e a profunda inserção das instituições públicas na sociedade importam muito mais do que a implementação de políticas públicas específicas. Para o desempenho econômico de longo prazo, o que 
importa é lidar com conflitos étnicos, o apoio popular à democracia e a estabilidade do regime político.

Essa perspectiva já está razoavelmente assentada na literatura acadêmica. O que permanece mal compreendido é o que explica a grande variação na robustez institucional dos Estados entre os países em desenvolvimento. A questão central é, então, o que faz um Estado forte?

Um aspecto muito interessante é que a maior parte da literatura dedicada à questão se orienta aos casos considerados clássicos do início da Europa moderna e dos Estados desenvolvimentistas do Leste Asiático no século XX, casos que por suas circunstâncias excepcionais (guerras interestatais com grave ameaça às soberanias, colapso do feudalismo e ameaças à segurança vindas da Guerra Fria) não podem ser tomados como um padrão aplicável a qualquer outro contexto. Ou seja, trata-se aqui de entender as variações na construção dos Estados em contextos “normais” ou ordinários.

Outro desafio para uma teoria contemporânea de construção do Estado em países de desenvolvimento tardio, como os latino-americanos, é o fato de que, diferentemente da experiência clássica europeia, as modernizações política e econômica não necessariamente ocorreram ao mesmo tempo nos mesmos lugares. Além disso, a tarefa consiste em produzir uma teoria do desenvolvimento institucional que leve em conta a história de longos períodos de estabilidade pontuados por períodos de mudança em determinados momentos críticos.

Ao focalizar quatro países da América Latina (Chile, Uruguai, Argentina e Peru), percebe-se que o desafio teórico representado pela comparação desses casos é duplo: por um lado, nenhuma das teorias sobre desenvolvimento político foi capaz de explicar satisfatoriamente as diferenças entre os níveis de robustez das instituições estatais naqueles países. De outra parte, nenhuma dessas teorias consegue tampouco explicar satisfatoriamente a estabilidade geral nas posições relativas desses países na comparação quanto à construção do Estado ao longo do tempo: há entre eles uma hierarquia de capacidade institucional (desenvolvimento político) que se manteve intrigantemente estável ao longo da história - Chile e Uruguai sempre numa posição melhor que Argentina e Peru.

As teorias dominantes sobre desenvolvimento político enfatizam as guerras interestatais e as ameaças à soberania dos Estados como variável explicativa (abordagem militarista) ou os efeitos deletérios da abundância 
de riqueza natural sobre os segmentos mais avançados das economias que os detêm (abordagem da doença holandesa). Mas elas sofrem de graves lacunas em sua aplicação à América Latina, por não conseguirem explicar as variações de capacidades estatais entre países que viveram contextos similares de relativa paz externa, ou entre países igualmente aquinhoados com fartos recursos naturais.

Por isso, Kurtz propõe uma nova teoria de construção do Estado na América Latina, que supere tanto a abordagem militarista quanto a da doença holandesa. A partir de uma visão do desenvolvimento político centrada na sociedade (que chama de abordagem sociofundacional), podem-se articular resultados de longo prazo com dinâmicas sociais e políticas subjacentes em duas conjunturas críticas: a consolidação das instituições políticas nacionais, após a independência, e o primeiro ciclo de incorporação eleitoral da massa da sociedade civil (extraelites), nos anos 1930.

A dependência da trajetória histórica dos países, nessa abordagem, aponta esses dois divisores de águas históricos que formataram as instituições e determinaram o desenvolvimento político daqueles Estados, produzindo dois mecanismos causais historicamente correlacionados:

1. A primeira conjuntura crítica corresponde às relações sociais e à dinâmica política que caracterizou o período do estabelecimento das instituições políticas nacionais: trabalho livre ou não; cooperação das elites ou não em delegar autoridade política ao centro. Onde o trabalho não era livre (economias agrárias com trabalho forçado), as elites eram muito ciosas do controle local do aparato coercitivo oficial, sem o qual estariam ameaçadas econômica e até fisicamente, e resistiram fortemente à introdução ou ao aumento de tributos necessários ao custeio de instituições estatais centralizadas. Isso retardou, nesses países, os esforços de centralização política, primeiro passo indispensável à construção dos Estados nacionais.

A abordagem é, portanto, sociofundacional porque sugere que os desenvolvimentos institucionais são efetivamente condicionados pelas realidades sociais subjacentes: as relações sociais da produção local definem se as elites locais veem a imposição de uma autoridade central como uma ameaça ou apenas como fardo que pode até ter implicações lucrativas.

O segundo dilema nessa primeira conjuntura crítica diz respeito ao comportamento das elites políticas em cada país: se elas conseguiram manter algum tipo compromisso de divisão competitiva do poder que tornasse 
possível a construção de instituições estatais nacionais sólidas ou se, ao contrário, envolveram-se em um jogo excludente, de soma zero, em busca da supremacia absoluta e da virtual eliminação dos oponentes.

A combinação dessas alternativas de desenvolvimento institucional produz, no argumento estilizado, a matriz quadrada a seguir:

Quadro 1 - Relações sociais $\times$ dinâmica política

\begin{tabular}{|c|c|c|c|}
\hline \multirow{2}{*}{\multicolumn{2}{|c|}{ soma zero/excludente }} & \multicolumn{2}{|c|}{ dinâmica política intraelites } \\
\hline & & competitiva & \\
\hline \multirow{2}{*}{$\begin{array}{l}\text { relações } \\
\text { sociais } \\
\text { (trabalho) }\end{array}$} & $\begin{array}{c}\text { não livres } \\
\text { (servis) }\end{array}$ & $\begin{array}{l}\text { atrofia institucional } \\
\text { Peru }\end{array}$ & construção estatal restrita \\
\hline & livres & $\begin{array}{l}\text { conflito intraelites e construção } \\
\text { institucional local } \\
\text { Argentina e Uruguai até } 1880\end{array}$ & $\begin{array}{c}\text { construção institucional nacional } \\
\text { Chile } \\
\text { Argentina e Uruguai após } 1880\end{array}$ \\
\hline
\end{tabular}

Fonte: elaboração própria.

2. A segunda conjuntura crítica é o momento histórico da incorporação ao processo político-eleitoral da grande massa da população urbana (classes médias e trabalhadoras), a ascensão da questão social. Se essa incorporação ocorreu tardiamente (por volta da Grande Depressão dos anos 1930 ou depois), uma aliança entre essas classes populares tornou-se possível, organizada em torno da expansão das instituições estatais e de uma estratégia de desenvolvimento baseada em subsídios à indústria nacional e na substituição de importações ("populismo"), para fazer frente à depressão econômica. Nesses casos, a principal via de emprego da classe média era tipicamente estatal, orientando o segmento a gerenciar esse Estado protecionista.

Contrariamente, a classe média incorporada ao processo político-eleitoral antes da Grande Depressão, nos anos dourados da economia privada exportadora e de ampla hegemonia de políticas liberais, tornou-se um ator social profundamente vinculado ao setor privado, sem praticamente nenhum interesse em contribuir para um Estado forte, que era visto mais como uma fonte de impostos do que como fonte de emprego.

Numa abordagem de trajetória dependente do processo de construção do Estado, as dinâmicas causais exibem tendência inercial: os efeitos das 
variáveis independentes são fortemente determinados pelo passado. Assim, fatores que poderiam ter iniciado um círculo virtuoso de construção do Estado num determinado ponto do tempo não necessariamente repetirão o mesmo efeito posteriormente. É por isso que esse modelo explicativo baseia-se em duas conjunturas críticas que produzem dois mecanismos causais complementares.

No caso dos países latino-americanos, a trajetória histórica mais favorável a uma robusta construção estatal é aquela que combina o legado de fortes instituições, proporcionado por relações oligárquicas cooperativas, assentadas, por sua vez, em relações sociais de trabalho livre ( a partir da época da independência), com uma aliança entre a classe média e a classe trabalhadora, no século XX, proporcionada pela entrada tardia dessas classes no sistema político-eleitoral (a partir da Grande Depressão).

Uma dificuldade recorrente para as teorias de construção do Estado é como medir as capacidades estatais. Muitos têm recorrido à capacidade extrativa, ou capacidade fiscal, medida pela proporção entre receita fiscal e renda nacional, como a melhor aproximação para dimensionar as capacidades estatais, e esse é também o caminho escolhido por Kurtz. Mas o uso desse indicador apresenta problemas.

Com efeito, é problemática sua assunção de que os baixos níveis de receita fiscal (como percentagem do produto interno bruto) são mais relacionados com escolhas políticas do que com capacidades estatais apenas nas economias avançadas (como, por exemplo, quando se compara os Estados Unidos com a Escandinávia), sendo que não se observa essa relação nos países subdesenvolvidos, como os da América Latina, o que autorizaria tomar os níveis de receita fiscal como um bom indicador das capacidades estatais neste continente.

Mas, tomemos o exemplo da comparação do Brasil com o Chile: embora os níveis brasileiros de receita fiscal tenham sido, ao longo do tempo, substancialmente maiores que os chilenos, sob todos os outros aspectos o Estado chileno apresentou historicamente melhores condições de capacidades estatais que o Estado brasileiro.

Nesse sentido teria sido proveitoso para a abordagem de Kurtz que ele tivesse dialogado mais profundamente com a literatura sobre capacidades estatais que enfatiza a sua dimensão política - como aparece nos conceitos de capacidade política (Grindle, 1996), de autonomia inserida (Evans, 2004), 
de interdependência dirigida (Weiss, 1998) e de sinergia Estado-sociedade (Ostrom, 1996) - especialmente no que se distancia e avança em relação às abordagens centradas nas dimensões burocrática e coercitiva do Estado.

Contudo, Kurtz aponta ainda um interessante resultado do processo de construção do Estado na América Latina: as melhores situações são encontradas em lugares com nenhuma ou pouca herança das instituições burocráticas do período colonial; na verdade, na periferia do antigo sistema colonial, como Chile e Uruguai.

Ao contrário, países do velho centro do império colonial, que herdaram muito de sua burocracia, tornaram-se os piores exemplos em termos de capacidades estatais. Essa constatação reforça a tese, antiga, mas ainda frequentemente reafirmada, sobre o legado institucional prejudicial da colonização ibérica quando comparado com o da colonização britânica (Mahoney, 2010).

Contudo, aqui a análise de Kurtz sujeita-se à crítica de tomar esse legado colonial de maneira uniforme, com as diferentes trajetórias sendo determinadas mais pela oposição centro-periferia que por padrões distintos de colonização, como propõe Mahoney (2010), ao falar de um modelo mercantilista (tipicamente ibérico, entre os séculos XV e XVII) e outro liberal (tipicamente britânico, a partir do século XVIII) de colonialismo.

Outra objeção que se pode fazer à sua proposta teórica diz respeito à separação estanque entre os dois processos caracterizadores das duas conjunturas críticas apontadas: cooperação interelites e incorporação de segmentos extraelites no sistema político. Kurtz condiciona a possibilidade da cooperação interelites ao contexto de um sistema político exclusivamente dominado pelos interesses das classes dominantes. Assim, se a democratização ocorre "cedo demais" e os segmentos extraelites alcançam real influência, essa cooperação interelites em prol de um desenvolvimento institucional pode quebrar-se rapidamente, inviabilizando a reunião dos recursos materiais necessários a uma boa construção do Estado.

A rigidez determinista do argumento, levada ao extremo, pode conduzir à conclusão, um tanto extravagante, de que quanto mais cedo um país tenha se democratizado na América Latina, mais difícil foi seu processo de construção do Estado. Uma conclusão que praticamente contrapõe democratização a construção estatal e equivaleria a condenar a América Latina à não democracia, além de não encontrar respaldo em muitas das experiências históricas latino-americanas. 
Ademais, o tempo de experiência democrática pode ser justamente uma variável explicativa chave para melhores desempenhos em termos de desenvolvimento institucional e de construção do Estado, como veremos adiante, ao analisar a obra de Huber e Stephens (2012).

De qualquer forma, a abordagem de Kurtz, ao adotar uma explicação baseada em dependência da trajetória que lança mão de duas conjunturas críticas, filia-se a um emergente conjunto de abordagens teóricas que confere peso à explicação histórica baseada em sequências de eventos críticos, como nas abordagens de conjunturas críticas sequenciais (Büthe, 2002), de cadeia causal de longo prazo (Pierson, 2004) e de sequência histórica causal (Mahoney, 2009).

Vejamos agora as possibilidades que se abrem com a utilização dessa abordagem sociofundacional de construção estatal, de Kurtz, para interpretar a experiência brasileira de desenvolvimento e a trajetória política e institucional do país.

A primeira conjuntura crítica apontada pelo autor (emergência do Estado nacional) encontrou o Brasil com mercado de trabalho coercitivo (escravo) e um processo de competição oligárquica representado pelo parlamentarismo monárquico. Assim, no que diz respeito às alternativas de desenvolvimento institucional, o país deveria ser posicionado no quadrante da "construção estatal restrita", curiosamente o único quadrante vazio no argumento estilizado de Kurtz.

A segunda conjuntura crítica (incorporação da massa da população urbana no processo político-eleitoral) chegou ao Brasil tardiamente, após a Grande Depressão, o que permitiu a aliança entre a classe média e a classe trabalhadora em torno de um Estado desenvolvimentista, mas sobre a base institucional, herdada da conjuntura anterior, de uma limitada construção do Estado central.

Assim, se o caso brasileiro não era o de um Estado atrofiado, como o Peru, tampouco foi um caso de um completo e bem-sucedido processo de construção do Estado, como o Chile e o Uruguai. Isso sugere a hipótese de uma terceira conjuntura crítica para o caso brasileiro, quando aplicada à sua análise a abordagem de Kurtz.

Se compararmos Brasil e Argentina, por exemplo, o cenário de capacidade institucional emerge muito mais favorável à Argentina até o final dos anos 1980. Nos termos do quadro teórico-analítico de Kurtz, a Argentina herdou, de seu processo de formação do Estado nacional no século XIX, 
uma trajetória positiva de construção do Estado, ao menos a partir de 1881, ainda que tenha se enredado, no século XX, num ciclo institucional populista que prejudicou muito suas capacidades estatais. O Brasil, ao contrário, partiu de um processo de construção estatal restrita e assim permaneceu por longo tempo.

De fato, Schneider (1999) aponta as quatro características essenciais do Estado brasileiro em suas relações com a economia e a política entre $1930 \mathrm{e}$ 1980: 1) "capitalismo político", em que lucros e investimentos dependem de decisões estatais; 2) discurso dominante industrialista e intervencionista; 3) exclusão política da maioria da população; 4) burocracia fluida e fracamente institucionalizada, na qual predominam nomeações e fidelidades políticas.

Todavia, duas décadas depois o quadro já era bastante diferente: num estudo comparativo entre dezoito países da América Latina, conduzido pelo Banco Interamericano de Desenvolvimento (BID), a burocracia brasileira foi apontada como a melhor, tanto em termos de profissionalização, medida pelo grau de autonomia e pela existência de garantias efetivas aos servidores públicos contra o autoritarismo, a politização e as pressões por favores e benefícios privados, como de capacidade técnica, medida pelas características dos sistemas remuneratórios e de avaliação de desempenho dos servidores públicos (IDB, 2006).

Considerando esse novo cenário, Schneider (2013) reconheceu que o Brasil foi uma boa surpresa na região, mostrando, juntamente com o Chile, a melhor situação em termos de governança efetiva, estabilidade política e capacidade burocrática na América Latina.

Mas o que aconteceu no intervalo dessas duas décadas que explique tão diferente situação do país. Que mudanças institucionais poderiam explicar isso? Nos termos da abordagem de $\operatorname{Kurtz}(2013)$, se uma mudança tão profunda não é explicada pelas duas conjunturas críticas anteriores, como poderíamos explicar essa trajetória? Especialmente se assumimos, com o autor, que existe uma sólida estabilidade nos padrões históricos de construção do Estado e de capacidades institucionais entre os países da América Latina.

A hipótese aqui sugerida é que para explicar esse enigma, sob o prisma teórico-analítico de Kurtz, precisamos tomar o processo de democratização do Brasil na década de 1980, após a ditadura, como uma terceira conjuntura crítica, cuja síntese histórica é a nova Constituição do país, promulgada em outubro de 1988. 
Primeiramente, porque a democratização do Brasil começou quando apenas se iniciava a hegemonia neoliberal no mundo e todos os desdobramentos da globalização. Assim, as pressões pela abertura da até então fechada economia, embora crescentes, não chegaram a ser irresistíveis.

Em segundo lugar, a democratização encontrou o país sob robusta onda de ascensão dos movimentos trabalhistas, expressa nas massivas greves operárias a partir do final dos anos 1970 - principalmente no ABC paulista - e na criação do Partido dos Trabalhadores (PT), em 1980, e da maior central sindical do país, a Central Única dos Trabalhadores (CUT), em 1983.

Por fim, para além da mobilização trabalhista, esse período testemunhou também uma intensa mobilização social, expressa nas maiores multidões já reunidas nas ruas clamando pelo direito de eleger diretamente o presidente da República (a famosa campanha das "Diretas Já"), bem como na enorme mobilização em torno das emendas populares à Constituinte, que reuniram vários milhões de assinaturas.

Uma vez que o balanço das forças políticas dentro do Congresso Constituinte era bastante favorável aos setores mais conservadores, muitos deles, inclusive, apoiadores e herdeiros do regime ditatorial, a confluência dessas circunstâncias resultou numa Constituição que assumiu um padrão institucional híbrido de Estado e do relacionamento Estado-sociedade: bastante intervencionista na vida econômica, mas ao mesmo tempo marcada por um forte movimento em direção à descentralização e ao controle público sobre o Estado, assim como por um importante compromisso com a construção de um Estado de bem-estar social no Brasil.

Estritamente no que concerne à promoção de capacidades estatais e à consequente robusta construção do Estado, as principais características da nova Constituição foram:

1. Intervencionismo econômico estatal, com a manutenção de empresas estatais estratégicas (Petrobrás, Eletrobrás, Telebrás, bancos), monopólio estatal sobre recursos minerais, forte regulação do mercado de trabalho e institucionalização da ação planificadora do Estado (PPA, planos regionais de desenvolvimento).

2. Convergência a uma burocracia meritocrática (weberiana), com a exigência de concurso público para ingresso e de sua organização em carreiras (ascensão funcional por mérito). 
3. Fortalecimento da participação e do controle social, por meio de redes de conselhos de políticas públicas, abertura de canais de participação pública direta na gestão dessas políticas e fortalecimento da rede de agências de controle (Banco Central, Tribunal de Contas da União, Ministério Público da União).

4. Início da construção de um Estado de bem-estar social, por intermédio do estabelecimento da cobertura pública e universal de serviços de educação e de seguridade social.

Como o repertório institucional não poderia ser emprestado do regime ditatorial, o quadro institucional resultante poderia ser representado em um duplo movimento: democratização (descentralização, transparência e responsabilização) e recuperação das principais bases do Estado nacional-desenvolvimentista dos anos 1950 e 1960, embora não mais baseado no padrão de desenvolvimento por substituição de importações.

Incluir uma terceira conjuntura crítica na explicação não resolve todo o problema da análise: com efeito, os resultados recentes sobre redução da pobreza e da desigualdade, junto às resultantes alterações na pirâmide de renda do país, com a classe de rendimentos intermediários tornando-se a maior parte da população, levanta outra intrigante questão: por que esses expressivos resultados não apareceram antes, imediatamente após a Constituição?

Para responder a essa questão sobre um desenvolvimento associado à redução das desigualdades num país que historicamente sempre exibiu trajetória inversa, precisamos de outra hipótese, baseada na teoria das constelações de poder, mirando as coalizões políticas que possibilitaram aquele caminho. Isso nos leva ao livro de Huber e Stephens (2012).

\section{A política da mudança institucional}

Huber e Stephens (2012) argumentam que as forças políticas podem trazer mudanças redistributivas relativamente pacíficas na América Latina. Diferentemente de outras abordagens, que enfatizam as condições econômicas, reduções de constrangimentos externos e o ciclo de alta nos preços das commodities, aqui a variável independente, explicativa das mudanças redistributivas, são as forças políticas.

De acordo com os autores, o que tradicionalmente se focaliza na América Latina é o crescimento econômico e a redução da pobreza, não a desigual- 
dade. Mas mudanças na opinião pública (crítica crescente aos programas de austeridade patrocinados pelo Fundo Monetário Internacional) e a crescente percepção de que a desigualdade pode obstaculizar o crescimento econômico trouxeram o tema ao centro do debate.

Os economistas usualmente têm explicado a desigualdade pela distribuição desigual de meios produtivos, frequência das crises macroeconômicas e pelas heranças da colonização (como exploração e baixos níveis educacionais). Os cientistas políticos têm atribuído a ausência de reformas distributivas à natureza disfuncional das instituições políticas.

Mas na primeira década do século XX, a América Latina testemunhou uma virada histórica em direção a políticas sociais redistributivas, as quais pela primeira vez produziram um declínio da desigualdade na região. Huber e Stephens explicam as diferenças nas políticas sociais redistributivas e na desigualdade, entre os países e através do tempo, baseando-se numa combinação de análise quantitativa com análise histórica comparativa de cinco casos do continente (Brasil, Chile, Uruguai, Argentina e Costa Rica) e dos dois países ibéricos, Portugal e Espanha.

No argumento, a democracia é um dos mais importantes determinantes da política social redistributiva. Um mecanismo pelo qual a democracia promove políticas sociais igualitárias é a facilitação ao desenvolvimento de partidos de esquerda e de seu acesso ao poder. As estruturas internacionais de poder também afetam o destino das políticas sociais igualitárias, mas é o investimento em capital humano que detém o papel central. Isso porque a seguridade social não é muito redistributiva e às vezes chega mesmo a ser perversamente regressiva na América Latina, enquanto os gastos com educação, saúde e transferências de renda focalizadas são bastante redistributivos. De fato, a correlação entre níveis nacionais de pobreza e habilidades cognitivas médias é muito alta.

De acordo com Huber e Stephens, da ampla literatura, as principais teorias sobre os determinantes do Estado de bem-estar social nos países avançados podem ser agrupadas em três grupos: (1) lógica do industrialismo (Williamson; os Estados de bem-estar social são vistos como subproduto do desenvolvimento econômico); (2) Estado-cêntrica (Orloff, Skocpol; a autonomia relativa da burocracia é enfatizada); e (3) Recursos de poder (Stephens, Korpi; foco na distribuição de poder e de propriedade entre as classes sociais). 
Entretanto, na América Latina temos muito menos literatura sobre Estado de bem-estar social ou, mais modestamente, sobre regimes de política social. Sua primeira geração, iniciada no final dos anos 1970, enfatizava as respostas das elites às pressões de grupos politicamente influentes, a competição eleitoral e, nos casos dos regimes autoritários, as tentativas das elites de cooptar e incorporar grupos importantes. Uma segunda geração de estudos associou a origem e as formas dos Estados de bem-estar social na América Latina com o próprio processo de construção do Estado e o desenvolvimento tardio e dependente. Outros destacaram a emergência de novas coalizões políticas e sociais internas dominantes ou estruturas políticas e econômicas internacionais que forçaram a adoção de determinados modelos de política social.

Contribuições mais recentes resultaram numa tipologia que identifica três modalidades de Estado de bem-estar social na América Latina:

1. Universalismo estratificado: produto de elites em conflito disputando apoio popular (Uruguai, Argentina, Chile).

2. Dualismo: monopólio estatal de elite relativamente coesa, adotando em relação ao restante da população uma estratégia de cooptação e repressão (Brasil, México).

3. Regimes excludentes: elites predatórias (Bolívia e boa parte dos países da América Central).

No caso europeu, as diferenças entre a democracia cristã e a social-democracia, as duas maiores forças políticas a impulsionar o Estado de bem-estar social no continente, foram determinantes: enquanto a social-democracia foi mais universalista e igualitária, tanto em termos de gênero quanto em termos de classes, a democracia cristã foi centrada no modelo bismarckiano, baseado na ocupação e na contribuição individual e preponderantemente comprometido com os trabalhadores homens, vistos como os principais provedores dos lares. Esse último modelo foi o geralmente adotado na América Latina.

A partir daí, Huber e Stephens propõem a teoria das constelações de poder, que identifica três grupos de poder que determinam os resultados sociais e econômicos de um país:

1. O balanço de poder entre as classes sociais e os partidos políticos domésticos (fator explicativo central nas democracias capitalistas avançadas): no caso da América Latina, o desenvolvimento econô- 
mico foi historicamente tardio e dependente dos países avançados, além de ter herdado uma distribuição de terra altamente desigual e a predominância de uma classe de grandes proprietários.

2. A estrutura do Estado e das relações Estado-sociedade: mais importante na análise do desenvolvimento da política social na América Latina. Sob os regimes autoritários, o Estado era mais autônomo com relação à sociedade civil e a necessidade de incorporar a classe trabalhadora urbana emergente aumentou o problema da capacidade estatal.

3. As estruturas transnacionais de poder: muito mais importante na América Latina que nas economias avançadas. Durante a crise da dívida (anos 1980 e 1990) as pressões internacionais pela adoção da agenda neoliberal, inclusive a reforma da política social, eram insuportáveis.

Embora Huber e Stephens reconheçam as dificuldades em aplicar a teoria à América Latina - um ambiente com fraca democracia, desenvolvimento tardio e estrutura de classes muito diferente -, procuram demonstrar que o regime político e a esquerda política são os principais determinantes de políticas sociais igualitárias no continente.

Os autores definem classe social, numa combinação das abordagens marxista e weberiana, como um grupo de indivíduos que em virtude dos seus ativos é compelido a se engajar em atividades similares no processo produtivo se quiser fazer o melhor uso desses ativos. Com base nisso, identificam as seguintes classes sociais principais na América Latina atual:

- Classe trabalhadora informal

- Classe trabalhadora manual formal

- Trabalhadores não manuais (assalariados de nível técnico e baixa burocracia estatal)

- Pequena burguesia (pequenos empresários)

- Classe dominante (assalariados de nível universitário, alta burocracia estatal, executivos e capitalistas)

Comparada à europeia, a estrutura de classes na América Latina é inóspita à organização e à mobilização política das classes, devido ao grande tamanho dos setores informal e agrícola e ao tamanho limitado do setor industrial. Essas características também não favorecem a democracia. Essa estrutura de classes junto à elevada desigualdade resulta em fraca densidade da sociedade 
civil e reduz o potencial de mobilização política autônoma (não clientelista) das classes inferiores.

Por causa dessas diferenças, o modelo clássico europeu de poder da esquerda trabalhista (aliança formal entre trabalhadores organizados e partidos de esquerda) não se aplica à América Latina. Assim, o que faz os partidos do continente serem considerados de esquerda nessa abordagem é o seu compromisso ideológico com os valores do igualitarismo e da solidariedade e a natureza de seu apelo político às classes subordinadas.

Portanto, no lugar de uma identificação direta entre classes e partidos o elemento programático é que assume papel crucial na representação e na competição política latino-americana, uma vez que as preferências políticas dos partidos de esquerda geralmente favorecem programas sociais redistributivos que beneficiam a grande maioria dos cidadãos desprivilegiados.

Huber e Stephens identificam quatro contextos históricos de emergência dos partidos de esquerda na América Latina:

1. O da expansão das exportações baseada nos setores mineral-exportadores (primeira metade do século XX): Acción Democrática (Venezuela); Alianza Popular Revolucionaria Americana (Peru); Partido Socialista e Partido Comunista (Chile); Movimiento Nacionalista Revolucionario (Bolívia).

2. O da expansão industrial, sob governos populistas e a política de substituição de importações (anos 1940 a 1960): peronismo (Argentina); Partido Trabalhista Brasileiro (Brasil) e Partido Revolucionario Institucional (México).

3. O da luta contra os regimes autoritários (anos 1960 e 1970): Partido dos Trabalhadores (Brasil); Izquierda Unida (Peru) e Frente Amplio (Uruguai).

4. Um mais recente e menos claro, com apelo policlassista às classes média e baixa e forte compromisso com o investimento em capital humano e a redução da pobreza: Colorados (Uruguai) e Partido Liberación Nacional (Costa Rica).

Eles também identificam um efeito de "contágio da esquerda" responsável pelo aprofundamento da institucionalização dos sistemas partidários: à medida que os partidos de esquerda se consolidaram como organizações, demonstrando fortes compromissos programáticos, os partidos de centro 
e de direita foram forçados a segui-los, fortalecendo suas organizações e perfis programáticos.

Nesse sentido, partidos de esquerda têm enfatizado programas redistributivos voltados à maioria da população; partidos de centro têm enfatizado a democracia, governo honesto e modernização institucional, especialmente na educação; e partidos de direita têm se concentrado em redução de impostos e reformas previdenciárias que diminuam privilégios de alguns segmentos junto ao Estado.

Mas a grande assimetria de poder entre as classes na América Latina, em comparação com a Europa, enfraquece a posição contra-hegemônica dos partidos de esquerda - o fator-chave das políticas redistributivas - resultando em menores efeitos redistributivos das políticas sociais no continente, o que pode explicar, ao menos em parte, os níveis historicamente muito altos de desigualdade na região.

Analisados em perspectiva histórica, os regimes de política social exibem pesada dependência da trajetória: durante o desenvolvimento das políticas sociais até o fim da industrialização por substituição de importações, por volta dos anos 1980, o tamanho da classe trabalhadora urbana e a história democrática (contada em anos de democracia após 1945) foram os mais fortes determinantes dos esforços de bem-estar social a partir de 1980 .

Durante esse período pode-se observar duas trajetórias básicas, e alternativas, quanto à liderança do nascente Estado de bem-estar social: força política da esquerda democrática (Chile, Costa Rica, Uruguai) e cooptação pela elite autoritária de uma grande classe trabalhadora urbana (Brasil e Argentina).

Entre os países avançados, os quatro mecanismos responsáveis pela forte dependência da trajetória exibida pelas políticas sociais são:

1. Limitações estruturais: as opções políticas são fortemente limitadas pela configuração da constelação de poder em cada país e pelas estruturas internacionais de poder, em cada momento histórico.

2. Legados políticos: resiliência das reformas de políticas sociais implantadas pela esquerda, que os governos conservadores tiveram muita dificuldade em reverter, dado o apoio popular a elas.

3. Legados dos regimes de produção: complementaridades entre os regimes de produção e os regimes de Estado de bem-estar, como entre a industrialização por substituição de importações e o sistema contributivo bismarckiano de seguridade social. 
4. Hegemonia ideológica: como os movimentos políticos e sociais conformaram as preferências políticas tanto das elites quanto das massas populares.

O cenário socioeconômico na América Latina parece ser bom para permitir a formação de coalizões políticas favoráveis a políticas sociais redistributivas, uma vez que, dadas as condições de distribuição de renda, dois terços das famílias devem ter interesse econômico em reformas sociais igualitaristas. Mas por que esse terreno aparentemente favorável produziu até hoje tão poucas reformas distributivas, mesmo durante os períodos democráticos? A resposta é que a desigualdade de recursos materiais é acompanhada pela desigualdade de recursos políticos.

Mesmo assim, no período recente, entre 1970 e 2005, a variável mais importante para determinar o dispêndio social, a desigualdade e a pobreza é a democracia. Isso porque a democracia proporciona o fortalecimento político da esquerda, o que afeta a composição e a alocação dos gastos em políticas sociais.

Ao analisar o desenvolvimento das políticas sociais, da pobreza e da desigualdade na América Latina, desde 1980, Huber e Stephens identificaram dois períodos claramente demarcados: os anos da hegemonia neoliberal (1980 a 2000) e os anos seguintes, após a virada à esquerda no continente. De acordo com eles, durante o primeiro período, em apenas uma área (educação) ocorreu significativo impulso numa direção progressista (igualitária e inclusiva). A desigualdade, de modo geral, cresceu no período, provavelmente por causa da desindustrialização e da mudança tecnológica orientada a maior qualificação da mão de obra.

A virada do século foi também um momento de reviravolta para a política, as políticas sociais e a desigualdade na América Latina. Os governos de esquerda empreenderam novas políticas sociais progressistas. A desigualdade caiu com a expansão educacional, que reduziu o bônus educacional no mercado de trabalho, com as políticas de regulação desse mercado e de elevação do salário mínimo e com as políticas de transferência condicionada de renda.

\section{Conclusão: fundamentos sociais e políticos da mudança institucional}

Se aplicarmos o quadro teórico-analítico de Huber e Stephens (2012) ao Brasil, podemos perceber algumas complementaridades interessantes e promissoras com a abordagem de Kurtz (2013), uma vez que é facilmente 
identificável na terceira conjuntura crítica aqui proposta, nos termos de Kurtz (o processo de democratização do Brasil na década de 1980, após a ditadura, até a promulgação da nova Constituição do país, em 1988), uma importante mudança no balanço de poder entre as classes sociais e os partidos políticos, com a emergência do PT e da CUT.

Outra interessante aproximação entre as duas abordagens aparece na colocação de Huber e Stephens sobre os efeitos da democracia sobre a desigualdade social não serem imediatos, mas levarem algum tempo, em torno de vinte anos, para se fazerem sentir. É curioso notar que este é aproximadamente o tempo decorrido entre a terceira conjuntura crítica e a chegada do PT ao governo federal. Huber e Stephens sugerem que, na América Latina, esse lapso foi decorrente da maturação de reformas educacionais inclusivas, que reduziram o bônus educacional no mercado de trabalho, e do tempo demandado pela construção de fortes partidos de esquerda. Uma vez mais em sintonia com esse quadro teórico-analítico, a trajetória institucional do PT nesses anos revela exatamente a história da consolidação de um partido francamente minoritário à época da Assembleia Constituinte, quando detinha uma bancada de dezesseis deputados e nenhum senador, que vê sua representação institucional crescer ininterruptamente e conquista o governo federal, em 2002, com a maior bancada na Câmara dos Deputados e a segunda maior bancada no Senado Federal.

Ainda ancorados na abordagem de Huber e Stephens, podemos dizer que a nova constelação de poder inaugurada com a vitória eleitoral do PT, em 2002, deu início à hegemonia de uma coalizão desenvolvimentista no Brasil que proporcionou importantes mudanças na desigualdade social no país, por meio de três principais instrumentos:

- O ativismo do Banco Nacional de Desenvolvimento Econômico e Social (BNDES)

- A política de valorização do salário mínimo

- O fortalecimento e expansão das políticas sociais

O papel central desempenhado pelos bancos de desenvolvimento na América Latina já foi observado. No caso brasileiro, a atuação do BNDES e o acesso às suas linhas de crédito por pequenas e médias empresas impactou significativamente o crescimento do emprego no país (IDB, 2013).

Apenas entre 2007 e 2013, por exemplo, o número de micro, pequenas e 
médias empresas que contaram com recursos do BNDES saltou de 41 mil para 275 mil (crescimento de 570\%) com recursos disponibilizados que passaram, no mesmo período, de R $\$ 16$ bilhões para $\mathrm{R} \$ 64$ bilhões (crescimento de $300 \%$ ), o que, junto com os demais financiamentos do Banco, levaram-no a contribuir para a criação ou a preservação de quase 6 milhões de empregos, cerca de $12 \%$ de todo o emprego formal no país (Coutinho, 2014).

Do mesmo modo, a política de valorização do salário mínimo, com reajustes anuais acima da inflação, vem sendo quase consensualmente considerada um dos mais importantes fatores de redução da desigualdade social no país, além de contribuir para a constituição de robusto mercado consumidor doméstico de massas, que se apresenta como uma característica distintiva do atual modelo econômico em relação ao modelo vigente nos anos de hegemonia neoliberal.

Com efeito, o valor real do salário mínimo, que desde a década de 1980 se manteve praticamente estagnado em torno dos US\$100, conheceu vigorosa elevação nos anos da administração petista, praticamente dobrando seu valor real em dez anos e atingindo a faixa dos US\$ $300 \mathrm{em}$ 2013 (Ipea, 2014).

Por fim, a expansão dos programas sociais, especialmente o de transferência condicional de renda (Bolsa Família) ajudou a melhorar a renda e a reduzir a pobreza e a desigualdade. Exemplo disso, a distribuição de renda, medida pelo índice de Gini, que permaneceu praticamente inalterada na casa do 0,6 desde o final da década de 1980, experimentou inédito e substancial movimento de desconcentração a partir da virada do século, aproximando-se em 2013 do patamar de 0,5 (Ipea, 2014).

O impacto combinado dessas políticas resultou na formação de um grande mercado consumidor interno de massas, com a incorporação de uma massa de vários milhões de novos consumidores, que explica em grande parte a resistência da economia brasileira à crise financeira internacional deflagrada em 2008, com a manutenção de níveis historicamente baixos de desemprego mesmo com a recente estagnação do crescimento, e, principalmente, como o Brasil conseguiu reduzir a desigualdade de renda mesmo sofrendo as consequências dessa crise.

E o que explica essa situação relativamente inédita são as políticas econômicas e sociais postas em prática pelos governos do PT, liderando uma coalizão política desenvolvimentista. 
Assim, por meio da combinação dos dois quadros teórico-analíticos aqui apresentados, vimos que o Brasil experimentou um forte desenvolvimento de suas capacidades estatais entre 1980 e 2000 . Essa trajetória pode ser explicada por meio de uma conjuntura crítica representada pelo processo de democratização e pelo processo constituinte que o coroou.

Mas, se a nova arquitetura institucional resultante desse processo foi condição necessária para a construção de um tipo de Estado desenvolvimentista, não era condição suficiente. O pleno desenvolvimento dessa potencialidade dependia da constituição de nova constelação de poder capaz de empreender, no comando do país, o caminho do crescimento com redução da pobreza e das desigualdades e de modificar, ainda que tenuemente, estruturas econômicas e sociais que outrora pareciam imutáveis.

Ou seja, a conjuntura crítica do processo de redemocratização e da Constituição de 1988 forneceu o arcabouço institucional que permitiu ao Brasil construir, pela primeira vez, um tipo de Estado de bem-estar social com capacidades estatais mais efetivas para sua reprodução e expansão. Mas a velocidade dessa construção não foi determinada por essa conjuntura. Dependeu, antes, da consolidação de uma experiência democrática que proporcionou o fortalecimento político da esquerda e afetou a composição e a alocação dos gastos em políticas sociais. Isto é, dependeu da mudança no balanço de poder entre as classes sociais e os partidos políticos e da constituição de uma constelação de poder desenvolvimentista. Numa palavra, dependeu da política.

Assim, a análise dessas duas contribuições à literatura sobre dependência da trajetória e mudança institucional, Kurtz (2013) e Huber e Stephens (2012), além de revelar vários pontos de convergência entre elas, mostra as possibilidades que a sua utilização combinada abre para interpretar a experiência brasileira de desenvolvimento, seja pela sugestão de uma conjuntura crítica, formada pela década da democratização e da Constituição (1978-1988), seja pela identificação dos mecanismos - mudança no balanço de poder e constituição de uma coalizão desenvolvimentista - por meio dos quais se realizaram recentemente importantes modificações na estrutura social do país.

\section{Referências}

BARTELT, David (2013). A “nova classe média" no Brasil como conceito e projeto político. Rio de Janeiro: Fundação Heinrich Böll. 
BÜTHE, Tim (2002). “Taking temporality seriously: modeling history and the use of narratives as evidence". American Political Science Review, v. 96, n. 3, p. 481-93.

CAMERON, Maxwell \& HERSHBERG, Eric (2010). Latin America's left turns: politics, policies and trajectories of change. Boulder (CO): Lynne Rienner Publishers.

CAMPBELL, John (2010). "Institutional reproduction and change", em MORGAN, Glenn et al. (eds.). Oxford Handbook of Comparative Institutional Analysis. Oxford: Oxford University Press.

COUTINHO, Luciano (2014). “O desempenho do BNDES”. Apresentação à Comissão de Assuntos Econômicos e à Comissão de Relações Exteriores e Defesa Nacional do Senado Federal. Brasília, 25 mar.

CROUCH, Colin (2005). Capitalist diversity and change. Oxford: Oxford University Press.

DOCTOR, Mahukh (2012). "Inequality, social policy and State welfare regimes in development countries: the case of Brazil", em CONNELLY, J. \& HAYWARD, J. (eds.). The withering of the welfare State: regression. Basingstoke: Palgrave Macmillan.

EVANS, Peter (2004). Autonomia e parceria: estados e transformação industrial. Rio de Janeiro: Editora UFRJ.

FERREIRA, Francisco et al. (2013). Economic mobility and the rise of the Latin American middle class. Washington: IBRD/The World Bank.

FLORES-MACÍAS, Gustavo (2012). After neoliberalism: the left and economic reforms in Latin America. New York: Oxford University Press.

GRINDLE, Merilee S. (1996). Challenging the State: crisis and innovation in Latin America and Africa. Cambridge: Cambridge University Press.

HACKER, J.; PIERSON, P. \& THELEN, K (2013). "Drift and conversion: hidden faces of institutional change". Annual Meetings of the American Political Science Association. Chicago, 30 ago.

HUBER, Evelyne \& STEPHENS, John (2012). Democracy and the left: social policy and inequality in Latin America. Chicago: Chicago University Press. IDB - INTER-AMERICAN DEVELOPMENT BANK (2006). The politics of policies. Washington: IDB.

(2013). Bancos públicos de desarollo. Washington: IDB.

IPEA - INSTITUTO DE PESQUISA ECONÔMICA APLICADA (2014). Ipeadata: tabelas sobre evolução do salário mínimo real e do coeficiente 
de Gini. Disponível em: http://www.ipeadata.gov.br. Acesso em: 17 nov. 2014.

KURTZ, Marcus (2013). State building in Latin America. New York: Cambridge University Press.

LEVITSKY, Steven \& ROBERTS, Kenneth (eds.) (2011). The resurgence of the Latin American left. Baltimore (MD): Johns Hopkins University Press.

MAHONEY, James (2009). "The logic of historical explanation in the social sciences". Comparative Political Studies, v. 42, n.1, p. 114-46.

(2010). Colonialism and postcolonial development: Spanish America in comparative perspective. New York: Cambridge University Press.

MAHONEY, James \& THELEN, Kathleen (2010). Explaining institutional change. Cambridge: Cambridge University Press.

NERI, Marcelo (2010). A nova classe média: o lado brilhante dos pobres. Rio de Janeiro: FGV/IBRE/CPS.

OSTROM, Elinor (1996). "Crossing the great divide: coproduction, synergy and development”. World Development, v. 24, n. 6, p. 1073-87.

PIERSON, Paul (2004). Politics in time: history, institutions and social analysis. Princeton: Princeton University Press.

POCHMANN, Marcio (2012). Nova classe média? o trabalho na base da pirâmide social brasileira. São Paulo: Boitempo.

SCHNEIDER, Ben Ross (1999). "The Desarrollista State in Brazil and Mexico", em WOO-CUMINGS, M. (ed.). The developmental State. Ithaca (NY): Cornell University.

(2013). Hierarchical capitalism in Latin America. New York: Cambridge University Press.

SINGER, André (2012). Os sentidos do lulismo: reforma gradual e pacto conservador. São Paulo: Companhia das Letras.

SOUZA, Amaury \& LAMOUNIER, Bolívar (2010). A classe média brasileira. Rio de Janeiro: Elsevier, CNI.

SOUZA, Jessé (2012). Os batalhadores brasileiros: nova classe média ou nova classe trabalhadora? Belo Horizonte: Editora UFMG.

WEISS, Linda (1998). “The sources of State capacity”, em WEISS, Linda. The myth of the powerless State. Ithaca (NY): Cornell Press.

WEYLAND, Kurt; MADRID, Raúl \& HUNTER, Wendy (eds.) (2010). Leftist governments in Latin America: successes and shortcomings. Cambridge, New York: Cambridge University Press. 


\section{Resumo}

O debate sobre determinantes estruturais dos processos de desenvolvimento das sociedades contemporâneas é amplo e multifacetado. Duas vertentes especialmente profícuas dessa literatura são as abordagens que enfatizam os legados institucionais e os elementos de dependência da trajetória, de um lado, e as teorias que se apoiam na dinâmica política e social dessas sociedades para tentar explicar aqueles fatores estruturais. Duas recentes obras representativas dessas vertentes, Kurtz (2013) e Huber e Stephens (2012), são aqui analisadas, buscando-se apontar pontos de convergência entre elas e também as possibilidades de seu uso para interpretar a experiência brasileira de desenvolvimento. $O$ artigo conclui que a abordagem sociocêntrica de construção estatal, de Kurtz, e a teoria das constelações de poder, de Huber e Stephens, são ferramentas promissoras para contribuir com o avanço da agenda de pesquisa sobre desenvolvimento no Brasil.

Palavras-chave: construção estatal, constelações de poder, dependência da trajetória, mudança institucional, desenvolvimento no Brasil.

\section{Abstract}

The debate on structural determinants of development processes in contemporary societies is broad and multifaceted. Two particularly fruitful aspects of this literature are the approaches that emphasize the institutional legacy and path dependency elements, on the one hand, and theories which are based on the political and social dynamics of these societies, in order to try to explain those structural factors. Two recent representative works of these approaches, Kurtz (2013) and Huber and Stephens (2012), are analyzed here, seeking to point out aspects of convergence between them and also the possibilities that their use open to interpret the Brazilian development experience. The article concludes that socio-centric approach to state-building, by Kurtz (2013), and the theory of power constellations, by Huber and Stephens (2012), are promising tools to contribute to the advancement of the research agenda on development in Brazil.

Keywords: state building, constellation power theory, path dependence, institutional change, Brazilian development.

Recebido em 19 de novembro de 2014.

Aprovado em 22 de maio de 2015. 